\title{
Gebelikte Uygulanan Gastrointestinal Endoskopik Girişimlerde Hemşirenin Rolü
}

\author{
Nurse's Role in Gastrointestinal Endoscopic Procedures During Pregnancy
}

\author{
Nuray AKYÜZ*, Şerife Gözde TOHUMAT**
}

İletişim/Correspondence: Nuray AKYÜZ Adres/Adress: İstanbul Üniversitesi Florence Nightingale Hemşirelik Fakültesi,

Abide-i Hürriyet Cad. 34381 Şişli/ İstanbul Tel: 0212-440 00 00/ 27101 (Dahili 27101) Fax: 02122244990 E-mail: nakyuz1@hotmail.com

\section{$\ddot{O} Z$}

Gebelikte uygulanan gastrointestinal sistem (GIS) endoskopi ve invaziv işlemler, fetüsün maternal hipoksiye ve hipotansiyona duyarlı olması nedeniyle riskli olabilit. Diğer bir risk, anneye verilen ilaçların ve/veya maruz kalınan iyonize radyasyonun neden olduğu teratojenezisdir. Buna rağmen endoskopi, tedavi edici girişimlerin gerekli olduğu durumlarda, radyolojik ve cerrahi girişimlere göre daha güvenli bir seçenek olabilir.

Her zaman için yararlarına karşılık riskleri de değerlendirilerek endoskopiye karar verilmesi; gebe kadının ve fetüsün endoskopi öncesi, sirast ve sonrası yakın değerlendirmesinin/izleminin yapılması önemlidir.

Bu derlemede, endoskopinin gebe kadın ve fetüs üzerindeki etkileri irdelenmiş ve dikkat edilmesi gereken noktalara yer verilmiştir.

Anahtar Kelimeler: Endoskopi, gebe, fetüs, risk.

\section{ABSTRACT}

Performing gastrointestinal (GI) endoscopy and invasive procedures in pregnancy may be risky because the fetus is sensitive to maternal hypoxia and hypotension. Another risk factor is teratogenicity of the drugs administered to the mother and/or ionizing radiation being exposed. However, when therapeutic interventions are necessary, endoscopy may be a safer option than radiological and surgical interventions.

Careful assessment of both the benefits and the risks of endoscopy, close monitoring and follow-up of the mother and the fetus before, during and after the procedure is important.

In this article, effects of endoscopy on pregnant women and their fetuses are investigated and points to be considered are noted.

Key Words: Endoscopy, pregnant, fetus, risk.

\section{GíRiș}

Gastrointestinal sistem (GİS) endoskopi; özofagus, mide, duodenum (Üst GíS Endoskopi-Özofagogastroduodenoskopi) ve kalın bağırsağın (Alt GíS EndoskopiKolonoskopi) tanı ve tedavi amaciyla endoskop yard1miyla incelenmesidir. Ayrıca, Endoskopik Retrograd
Kolanjiyo Pankreatografi (ERCP) işlemi ile de safra yollarının ve pankreas kanalının görüntülenmesi sağlanabilir ve gerektiğinde tedavi girişimleri yapılabilir (ASGE 2014).

Gebelikte de tanı ve tedavi amaciyla endoskopik girişimlere gereksinim duyulabilir. Ancak gebelikte uygu-

*Yard. Doç. Dr. I. Ü. Florence Nightingale Hemşirelik Fakültesi, **Arş. Gör. İ. Ü. Florence Nightingale Hemşirelik Fakültesi

Yazının gönderilme tarihi: 16.05.2014

Yazının basım için kabul tarihi: 25.12.2014 
lanan GİS endoskopi ve invaziv işlemler anne ve fetüs için riskli olabilir. Çünkü fetüs maternal hipoksiye ve hipotansiyona duyarlıdır. Aşırı maternal sedasyon hipoventilasyon ve hipotansiyona; maternal pozisyon ve gebe uterusunun inferior vena kavaya baskısı ise uterus kan akımının azalmasına neden olabilir. Fetüs için diğer bir risk, anneye verilen ilaçların ve/veya maruz kalınan iyonize radyasyonun neden olduğu teratojenezisdir ve premature doğuma yol açabilir (Amaniti ve Tsaousi 2009; ASGE 2012). Buna karşıllk, tedavi edici girişimlerin gerekli olduğu durumlarda endoskopi, radyolojik ve cerrahi girişimlere göre daha güvenli bir seçenek olabilir (ASGE 2012; Manolaraki, Stroumpos ve Paspatis 2009).

Bilgilendirilmiş izinin hem fetüs hem de anne için olas1 riskleri içermesine dikkat edilmesi, endikasyon konulurken anne ve fetüste yol açabileceği yarar/zarar dengesinin çok iyi bir şekilde ortaya konması gerekir (SGNA 2014).

Gebelikte endoskopi uygulamaları için güçlü bir endikasyon bulunmalıdır (ASGE 2012; Cappell 2011). Belirgin ve devam eden GIS kanama, şiddetli/ inatçı bulant1/ kusma veya karın ağrısı, yutma güçlüğü/ ağrılı yutma, bağırsakta kitle varlığına yönelik şüphe, nedeni bilinmeyen ve kontrol altına alınamayan ishal, biliyer pankreatit, koledokolitiyazis veya kolanjit, biliyer veya pankreatik kanal yaralanması gibi durumlarda endoskopi yapılması gerekebilir (Amaniti ve Tsaousi 2009; ASGE 2012; Mitrut, Docea, Calina ve Streba 2013; SGNA 2014).

Her zaman için yararlarına karşılık riskleri de değerlendirilerek endoskopiye karar verilmelidir. Mümkünse endoskopi ikinci trimestere ertelenmelidir (Amaniti ve Tsaousi 2009; ASGE 2012; Cappell 2011). Her endoskopik işlem, fetüsün gestasyonel yaşına bakılmaksızın, bir kadın doğum uzmanının da işlem öncesi konsültasyonunu gerektirir. Fetal kalp hızı ve uterus kası1malarının izlemi açısından bir kadın doğum uzmanının görüşüne gereksinim vardır (ASGE 2012; Manolaraki ve ark. 2009).
Hemşirenin tüm GİS endoskopik işlemlerde ikinci ve üçüncü trimesterdeki hastalara işlem öncesi, sıraS1 ve sonrasında sirtüstü pozisyon verilmemesine dikkat etmesi gerekir. Aksi halde uterus aorta veya inferior vena kavaya bask1 yapabilir ve bu durum maternal hipotansiyon ve azalmış plasental perfüzyonla sonuçlanabilir. Çoğu endoskopik işlem vasküler basının sorun olmadığı sol yan pozisyonda yapılır. Vasküler bası işlem öncesi veya sonrası hastanın sağ kalçasının altına konulan bir yastıkla eğim oluşturarak veya hastay1 oturur pozisyonda işleme alarak önlenebilir. Gebe olan hastalar olmayanlara göre gastrik içeriğin ve sekresyonların aspirasyonuna daha yatkın olduğu için, bu konuda da dikkatli olunmalıdır (ASGE 2012).

Üst gastrointestinal endoskopik girişimler gebe olmayan hastalarda olduğu gibi gerçekleştirilir. Olgu serileri ve vaka-kontrol çalışmaları üst GIS endoskopinin hamilelikte güvenli ve etkili olduğunu göstermektedir. Kolonoskopinin güvenliğini değerlendiren çalışmalar ise azdır. Dikkat edilmesi gereken, gebeliğin geç dönemlerinde, hastalara kolonoskopi sırasında sirtüstü ya da yüzükoyun pozisyon verilmemesidir. Karına dıştan baskı gerekiyorsa, büyük bir dikkatle hafif bir şekilde uygulanmalı ve uterustan uzakta yönlendirilmelidir (ASGE 2012; Cappell 2003; Cappell 2011).

ERCP ise gebelik sürecinde tedavi edici girişim gerekiyorsa uygulanır. Biliyer pankreatit, semptomatik koledokolitiazis veya kolanjit olağan endikasyonlar1dır ve uygun şekilde tedavi edilmezse fetal kayıplara yol açabilir. İşlem deneyimli endoskopistler tarafından yapılmalıdır. Gebelikte yapılan ERCP'de en büyük sorun, fetüsün radyasyona maruz kalmasıdır. Her ne kadar hamilelerde fetal radyasyon dozunun büyük çoğunluğu radyasyon saçılımı sonucunda ortaya çıksa da, alt karın ve pelvis genellikle kurşun gömlekle korunmalıdır. Bu, radyasyonla ilişkili riski azaltma yöntemlerinden en etkili olanıdır ve floroskopi zamanını ve maruziyeti sinırlandırır. Ayrıca radyasyon dozu iyi ayarlanmalıdır. Daha yüksek miktarda radyasyon içerdiği için basılı x-ray filmleri çekmekten kaçınılmalıdir. Radyasyona maruz kalma süresi ve dozu mutlaka kaydedilmelidir (ASGE 2012; Mitrut ve ark. 2013). 


\section{Elektrokoter Kullanımı}

Amniyotik sıvı elektrik akımını fetüse iletebilir. Endoskopi hemşiresi topraklama pedini, uterus kateter ve topraklama pedi arasında kalmayacak şekilde yerleştirmelidir. Kaçak akımların fetüse geçme riskini en aza indirmek için bipolar elektrokoter kullanılabilir (Amaniti ve Tsaousi 2009; ASGE 2012). Sfinkterotomi ve hemostaz için kullanılan elektrokoter nispeten güvenli olmasına rağmen, elektrokoter kullanımı gerektiren polip çıkarılması (polipektomi) gibi işlemler doğum sonrasina ertelenmelidir (ASGE 2012).

\section{Endoskopide Yaygın Olarak Kullanılan İlaçların Gebelikte Güvenliği}

Amerikan Gıda ve İlaç Dairesi gebelik sırasındaki güvenliğine göre ilaçları 5 kategoriye ayırmıştır

Tablo 1. U.S. Food and Drug Administration-FDA (Amerikan Gıda ve İlaç Dairesi)'nın Gebelikte Kullanılan İlaçlarla İlgili Kategorileri

\begin{tabular}{|c|c|}
\hline Kategori & Tanımlama \\
\hline $\mathbf{A}$ & $\begin{array}{l}\text { Gebe kadınlar üzerinde yapılan yeterli ve } \\
\text { iyi kontrollü çalışmalarda herhangi bir fetal } \\
\text { anomali risk artışı gösterilmemiştir. }\end{array}$ \\
\hline B & $\begin{array}{l}\text { Hayvan çalışmalarında ilacın fetüs için bir } \\
\text { risk oluşturduğu ortaya konamamıştır; gebe } \\
\text { kadınlarda yeterli ve iyi kontrollü çalışmalar } \\
\text { yapılmamıştır ya da hayvan çalışmalarında } \\
\text { bir yan etki gösterilmiştir fakat gebe kadınlarda } \\
\text { yapılan yeterli ve iyi kontrollü çalışmalarla } \\
\text { fetüs için bir risk olduğu gösterilememiştir. }\end{array}$ \\
\hline $\mathrm{C}$ & $\begin{array}{l}\text { Hayvan çalışmalarıyla fetüs üzerinde yan etki } \\
\text { olduğu gösterilmiştir ve gebe kadınlar üzerinde } \\
\text { yeterli ve iyi kontrollu çalışmalar yapılmamıştır } \\
\boldsymbol{y} \boldsymbol{a} \boldsymbol{d} \boldsymbol{a} \text { hiçbir hayvan çalışması yapılmamıştır ve } \\
\text { gebe kadınlar üzerinde yeterli ve iyi kontrollü } \\
\text { çalışmalar yapılmamıştır. }\end{array}$ \\
\hline D & $\begin{array}{l}\text { Gebe kadınlar üzerinde yapılan yeterli, iyi } \\
\text { kontrollü ve gözlemsel çalışmalarla ilacın } \\
\text { fetüse riski gösterilmiştir. Ancak, tedavinin } \\
\text { yararları olası risklerinden fazla olabilir. }\end{array}$ \\
\hline $\mathbf{X}$ & $\begin{array}{l}\text { Hayvanlar ve gebe kadınlar üzerinde yapılan } \\
\text { yeterli, iyi kontrollü ve gözlemsel çalışmalarla } \\
\text { ilacın fetal anormalliklere neden olduğu } \\
\text { yönünde kanıtlar gösterilmiştir. İlacın gebe } \\
\text { ya da gebe olması muhtemel kadınlarda } \\
\text { kullanılması kontrendikedir. }\end{array}$ \\
\hline
\end{tabular}

Kaynak: American Society for Gastrointestinal Endoscopy (ASGE) (2012). Guidelines for endoscopy in pregnant and lactating women. Gastrointestnal Endoscopy, 76(1): 20.
(Tablo 1). A kategorisinde endoskopide kullanılan herhangi bir ilaç bulunmamaktadır. Endoskopik işlemlerde $B$ ve $C$ kategorisinden ilaçların kullanılması önerilmektedir. Çoğu işlem için sedasyon bilinçli sedasyon ya da anksiyoliz düzeyinde olmalıdır. Derin sedasyon gerekiyorsa eğitimli/deneyimli bir anestezist tarafindan uygulanmalıdır. Gebe hastada sedasyon uygulanırken artmış aspirasyon riski ve hava yolu açıklığı ile ilgili sorunlar açısından dikkatli olmak gerekir. Gebeliğe bağlı olarak hava yolunda orofaringeal dokularda ödem ve glotis açıklığın azalması gibi anatomik değişikliklerin olması; ayrıca kardiyopulmoner ve GIS'de ortaya çıkan fizyolojik değişiklikler gebe hastaların daha dikkatli bir şekilde izlemini gerektirir (ASGE 2012; Manolaraki ve ark. 2009; Mitrut ve ark. 2013; SGNA 2014).

\section{Narkotik Analjezikler:}

Yapılan iki çalışmada Meperidin'in (B kategorisi) teratojenik etkisinin görülmediği ve fetal kan beyin bariyerini hızlı bir şekilde geçen Morfin'e (C kategorisi) göre daha çok tercih edilebilir olduğu gösterilmiştir. Meperidin, uygulanmasından bir saat sonra sonra düzelen fetal kardiyak değişikliklere neden olabilir, fakat bu durum fetal distresi göstermez. Fentanil'in (C kategorisi) ise hızlı etki başlangıcı vardır ve Meperidin'e göre hastanın geri dönüş süresi daha kısadır, teratojenik değildir, düşük dozlarda verildiğinde güvenilir görünse de, gebelerde Meperidin Fentanil'e göre daha fazla tercih edilmektedir.

\section{Benzodiazepinler (D kategorisi):}

Diazepam gebe kadınların sedasyonunda kullanılmamalıdır. Diazepam'ın gebelikte sürekli kullanımı yarık damak ile, gebeliğin geç dönemlerinde kullanımı ise nörodavranışsal hastalıklarla ilişkilendirilmektedir.

Midazolam konjenital anomalilere neden olmaz. Meperidin yalnız başına yetersiz kalırsa tercih edilen bir Benzodiazepin olmalıdır. Mümkünse ilk trimesterde Midazolam'dan kaçınılmalıdır. 


\section{Flumazenil (C Kategorisi):}

$\mathrm{Bu}$ Benzodiazepin antagonistinin hamilelikte güvenli kullanımı ile ilgili az bilgi vardır. Nörodavranışsal değişikliklere neden olabilmektedir.

\section{Propofol (B Kategorisi):}

Gebelikte Propofol'ün yakın izlem gerektirmesi nedeniyle eğitimli/deneyimli bir anestezist tarafından uygulanması önerilir. İlk trimesterdeki güvenliği hakkında yeterli çalışma yoktur.

\section{Naloksan (B Kategorisi):}

Hızlı etkili opioid antagonisti olan Naloksan, IV uygulama sonrası 2 dakika içinde plasentayı geçer. Teratojenik etkisi yoktur. Yoksunluk belirtilerini hızlandırabileceği için Opioid bağımlısı annelerde kullanı$\mathrm{m} 1$ kontrendikedir. Yalnızca solunum depresyonu, hipotansiyon veya yakın izlemin mümkün olmadığ $\mathrm{du}-$ rumlarda uygulanmalıdır. Metabolize olan ilacın yeniden sedasyona neden olabileceği bilinmeli ve bu konuda hazırlıklı olunmalıdır.

\section{Glukagon (B Kategorisi):}

Glukagon ERCP sirasında yaygın kullanılan bir antispazmodik ajandır ve gebelikte kullanımı kontrendike değildir.

\section{Simetikon (C Kategorisi):}

Simetikon C kategorisinde bir ilaçtır, yaygın bir şekilde kullanılmaktadır ve muhtemelen güvenlidir.

\section{Topikal Anestetikler:}

Lidokain (B kategorisi) gibi topikal anestetikler sıklıkla ögürme refleksini azaltmak ve entübasyonu kolaylaştırmak amacıyla kullanılır. Kullanımı gerekli olduğunda hastaya, ilacı yutmak yerine gargara yapıp tükürmesi söylenerek yan etkilerinin azaltılması sağlanabilir.

Amerikan Anestezi Derneği (American Society of Anesthesiologists) ve Amerikan Kadın Hastalıkları ve Doğum Koleji'nin (American College of Obstetrics and Gynecology) ortak açıklamasında, şu anda kullanılan anestezik maddelerin standart konsantrasyonlarda kullanıldığında gebeliğin herhangi bir döneminde teratojenik etkiye sahip olmadığ belirtilmiştir (ASGE 2012; Mitrut ve ark. 2013; SGNA 2014).

\section{Antibiyotikler:}

Amerikan Gastrointestinal Endoskopi Derneği'nin (American Society for Gastrointestinal Endoscopy) rehberlerinde gebe olan ve olmayan hastalarda antibiyotiklerin profilaktik kullanım endikasyonunun benzer olduğu belirtilmektedir. Bazı antibiyotiklerin kullanımı gebeliğin bazı dönemlerinde güvenlidir. Bazılarının ise fetal yan etkileri nedeniyle kontrendike olduğunun bilinmesi önemlidir (ASGE 2012).

\section{Bağırsak Temizliği İçin Kullanılan Maddeler:}

Polietilen Glikol Elektrolit Solüsyonu (PEG) C kategorisinde sınıflandırılmıștır. Gebelikte güvenli kullanımı yeterince çalışılmamıştır. Sodyum fosfat solüsyonları ise (kategori C) sıv1-elektrolit dengesizliklerine neden olabilir, bu nedenle dikkatli kullanılmalıdır (ASGE 2012; Mitrut ve ark. 2013).

\section{SONUÇ VE ÖNERILER}

Gebelikte uygulanan GI endoskopik girişimler hem anne hem de fetüs için riskli olabilir. Endoskopi ekibinin, dolayısıyla hemşirelerin bu konuda bilgi ve deneyim sahibi olması gerekir.

Endoskopi yapılması ile ilgili dikkat edilmesi gereken konular şu şekilde sıralanabilir:

- Gebelikte endoskopi sadece güçlü endikasyon varsa yapılmalı, mümkünse ikinci trimestere ertelenmelidir. Plasentanın erken ayrılması, membran rüptürü ya da kontrolsüz eklampsi durumlarında ve doğuma yakın dönemde yapılmamalıdır.

- Bir kadın doğum uzmanı/ekibi tarafindan gebe kadının ve fetüsün yakın değerlendirmesinin/izleminin yapılması önemlidir.

- Gebelikte bilinçli sedasyonu içeren endoskopik işlemlerde B kategorisindeki ilaçlar kullanılmalıdır. 
Meperidin'in ve Midazolam'ın gereksinim duyulan en düşük etkin dozu tercih edilmelidir.

- Eğer derin sedasyon gerekiyorsa, bir anestezi uzmanı tarafindan uygulanmalıdır.

- Venakava veya aortik basıyı önlemek için işlem öncesi, sırası ve sonrasında hastalara sol pelvik eğim veya sol yan yatar pozisyon verilmelidir.

- İşlem süresi mümkün olduğunca kısa tutulmalıdır.

- Fetal kalp hızının izlemi için fetüsün gestasyonal yaşı ve mevcut duruma göre kişiye özgü karar verilmelidir.

- Gebelikte 24 haftadan önce, sedasyona başlamadan önce ve endoskopik işlem sonrası fetal kalp hızının doppler ile doğrulanması yeterli olacaktır. 24 haftadan sonra ise, işlem öncesi ve sonrası fetal kalp hızı ve uterus kontraksiyonları monitörize edilmelidir.

- İşlemin yenidoğan ve pediatrik servisi olan bir kurumda yapılması sağlanmalıdır. Gerektiğinde müdahale edebilecek uzman bir ekibin varlığı da önemlidir.

- Terapötik ERCP hamilelikte genellikle güvenlidir. Fakat anneye olan risklerin ve fetusun radyasyon maruziyetinin en aza indirilmesi için gerekli önlemler alınmalıdır.

- Hemşire tarafindan işlem öncesi, sırası ve sonrasında hastanın yaşam bulgularını yakından izlenmelidir.

- Elektrokoter kullanılmasi gerekiyorsa, bipolar elektrokoter kullanılmalıdır. Eğer monopolar elektrokoter kullanılacaksa, amniyon sivisı yoluyla elektrik geçişini azaltmak için topraklama pedleri uygun bölgeye yerleştirilmelidir.
- Endoskopik işlemler için antibiyotik seçimi yapılırken, hastaya ait faktörler ve fetal gelişim dönemi göz önünde bulundurulmalıdır. Her ne kadar birçok antibiyotiğin gebelikte kullanımı fetal gelişimin belirli aşamalarında güvenli ise de, bazılarının kontrendike olduğu unutulmamalıdır (ASGE 2012; Mitrut ve ark. 2013; SGNA 2014).

\section{KAYNAKLAR}

American Society for Gastrointestinal Endoscopy (ASGE) (2014). Endoscopic Procedures, http://www.asge.org/press/press. aspx?id=548 (03.12.2014)

Amaniti, E., Tsaousi, G. (2009). Sedation in GI endoscopy: Safety for both the pregnant woman and fetus (letter to the editor). Annals of Gastroenterology, 22(3): 203-204.

American Society for Gastrointestinal Endoscopy (ASGE) (2012). Guidelines for endoscopy in pregnant and lactating women. Gastrointestnal Endoscopy, 76(1): 18-24.

Cappell, M. S. (2011). Risks versus benefits of gastrointestinal endoscopy during pregnancy. Nature Reviews Gastroenterology and Hepatology, 8: 610-634.

Cappell, M. S. (2003). The fetal safety and clinical efficacy of gastrointestinal endoscopy during pregnancy. Gastroenterol Clin North Am., 32(1): 123-179.

Manolaraki, M. M., Stroumpos, C., Paspatis, G. A. (2009). Sedation in gastrointestinal endoscopies. Annals of Gastroenterology, 22(2): 90-96.

Mitrut, P., Docea, A. O., Calina, C. D., Streba, L. (2013). Endoscopy in pregnancy, http://www.intechopen.com/download/get/ type/pdfs/id/41906 (30.01.2014).

Society of Gastroenterology Nurses and Associates (SGNA) (2014). Pregnant\&LactatingWoman, http://www.sgna.org/issues/sedationfactsorg/specialcircumstances/pregnant.aspx (30.01.2014). 